\title{
Spontaneous closure of a myopic macular hole with retinal reattachment in an eye with high myopia and staphyloma: a case report
}

\author{
Jia Yu', Chunhui Jiang ${ }^{1 *}$ and Gezhi Xu,
}

\begin{abstract}
Background: Macular hole related retinal detachment is a common entity with poor surgical prognosis in highly myopic eyes. We describe the first case of spontaneous closure of a macular hole with complete retinal reattachment in a highly myopic eye with posterior staphyloma.

Case presentation: A 64-year-old Chinese woman with high myopia was diagnosed as having a macular hole-related retinal detachment with vitreo-retinal traction in her right eye by optical coherence tomography.

Thirty-three months later, the macular hole closed, with formation of a lamellar hole and decreased retinal detachment. Twelve months later, retinal reattachment was found to have occurred, accompanied by the development of macular retinoschisis. Fifty-four months after initial examination, the retina remained attached with a lamellar hole and retinoschisis in the macular area. The vitreo-retinal traction persisted during the follow-up period.

Conclusion: As evidenced by the current case, in highly myopic eyes, the vitreoretinal traction force, which contributes to a macular hole and retinal detachment, could be partially released by the development of a lamellar hole or foveal schisis. This reduction of traction might contribute to retinal reattachment.
\end{abstract}

Keywords: Myopia, Macular hole, Retinal detachment, Optical coherence tomography

\section{Background}

Macular hole related retinal detachment is a common entity in highly myopic eyes [1]. Results of surgical procedures, like pneumaticretinopexy and pars plana vitrectomy combined with other techniques, have not had favorable outcomes [2-5]. In contrast to common reports of spontaneous closure of idiopathic macular holes [6-8], reports of spontaneous closure of highly myopic macular holes have been exceedingly rare [9]. We report here the first case of spontaneous closure of a macular hole with complete retinal reattachment in a highly myopic eye.

\section{Case presentation}

A 64-year-old female visited our hospital for poor vision in her right eye. Ophthalmological examination indicated

\footnotetext{
* Correspondence: chhjiang70@163.com

${ }^{1}$ Department of Ophthalmology, Eye \& ENT Hospital of Fudan University, 83

Fenyang Road, Shanghai 200031, People's Republic of China

Full list of author information is available at the end of the article
}

her vision was counting fingers and diffuse chorioretinal atrophy at the posterior pole was observed. A B scan showed posterior staphyloma and a localized retinal detachment at the posterior pole. An A scan showed the axial length was $31.37 \mathrm{~mm}$. Optical coherence tomography (OCT, Cirrus HD-OCT, Carl Zeiss Meditec, Dublin, CA, axial resolution $5 \mu \mathrm{m}$ ) revealed a fullthickness macular hole, $66 \mu \mathrm{m}$ in diameter, accompanied by retinal detachment and vitreo-retinal traction from the posterior hyaloid membrane that was attached to the macular area (Figure 1a and b). The patient chose to be observed after reviewing the risks and benefits of surgery. Thirty-three months later, the macular hole was closed, with the formation of a lamellar hole and decreased retinal detachment (Figure 1c and d). Twelve months later, retinal reattachment was observed to be complete, accompanied by the development of macular retinoschisis. As indicated by subsequent OCT scans, such a condition remained stable, and vision remained at counting fingers until 54 months after the initial examination. The posterior 


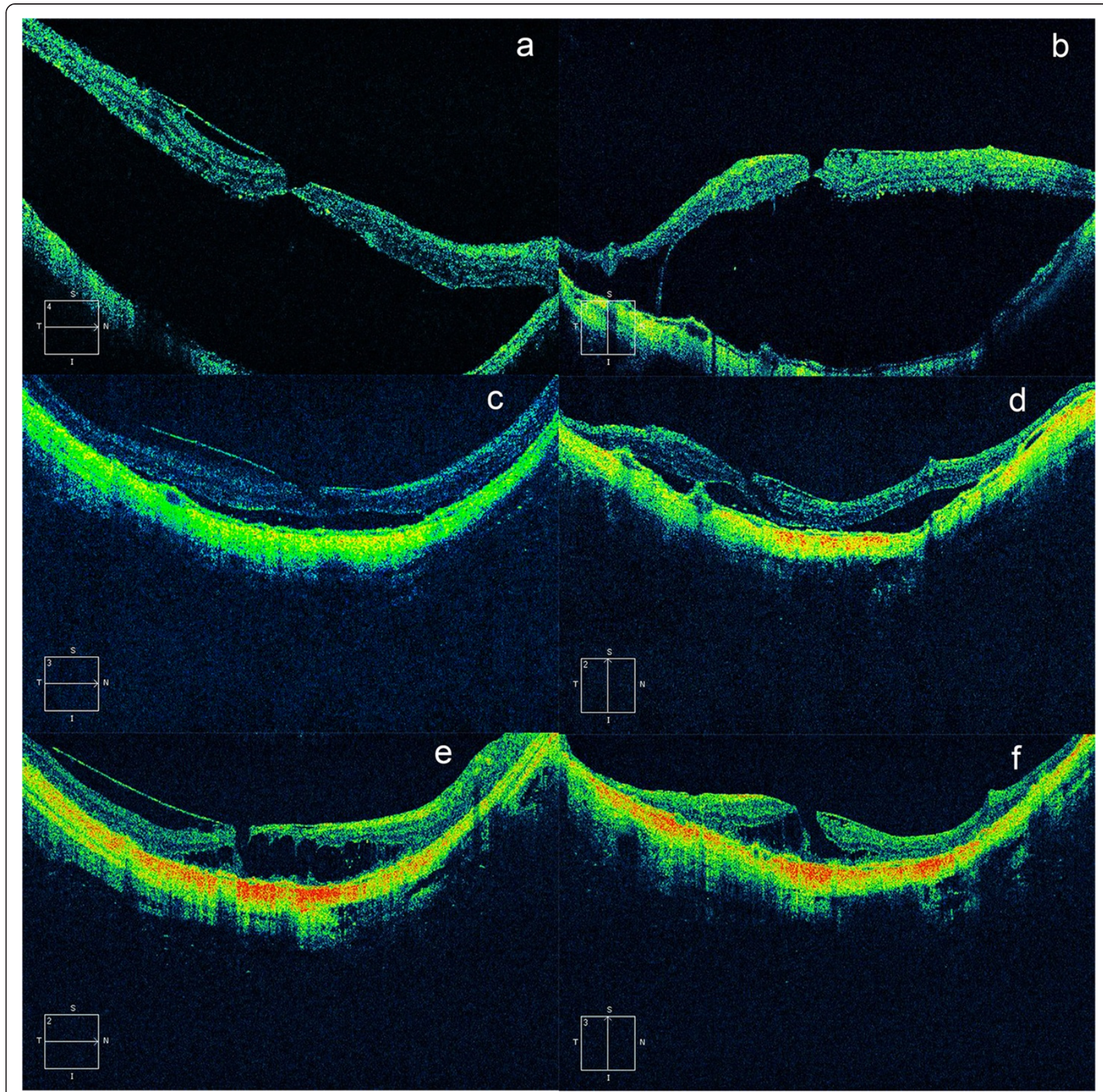

Figure 1 Spontaneous closure of a macular hole and complete retinal reattachment in a highly myopic eye. Panels a, $\mathbf{c}$ and $\mathbf{e}$ were

horizontal scans, while panels $\mathbf{b}, \mathbf{d}$, $\mathbf{f}$, were vertical scans. Retinal detachment and vitreoretinal traction caused by the posterior hyaloid membrane were presented $(\mathbf{a}, \mathbf{b})$; a full thickness macular hole was noted accompanied by para macular schisis inferior to the macula (b). The macular hole was closed (33 months later) and a lamellar hole formed with decreased retinal detachment (c, d). The retina (another 21 months later) stayed completely reattached with macular retinoschisis surrounding the fovea. The posterior hyaloid was detached from the inner surface of the retina in a wider area throughout the follow-up (e, f).

hyaloid membrane was detached from the inner surface of the macula in a wider area during the follow-up (Figure 1e and $f$ ).

\section{Conclusion}

Recently, Li et al. reported the first case of spontaneous closure of a highly myopic macular hole, which was ascribed to the release of the vitreoretinal tractional force [9]. However, in the current case, vitreo-retinal traction from the posterior hyaloid membrane was found initially and remained present throughout the follow-up, thus the release of vireoretinal traction was unlikely. In this case, closure of the hole might have happened first, albeit the reason not fully being understood. The small 
size of the macular hole in the current case might be one cause. It has been reported that in both emmetropic and highly myopic eyes, small macular holes were more likely to be closed after surgical treatment $[10,11]$. After closure, however, the retinal detachment was reduced with the reabsorption of subretinal fluid by the retinal pigment epithelium (RPE) pump, though this might be inefficient because of the degeneration and atrophy of the RPE and choroid. However, the vitreo-retinal traction that was still present prevented the retina from laying down and, consequently, these two forces might actually lead to tissue dehiscence; i.e., the development of a lamellar hole and macular schisis. In highly myopic eyes, traction forces caused by the stretching of the eyeball and relative shortening of the retina, as well as vitreo-retinal traction by the posterior hyaloid membrane, contribute to the development of many macular disorders [12-14]. With the formation of a lamellar hole, the retina might be elongated by the dehiscence of the tissues, resulting in reduction of the traction force. This could be partially supported by the findings that a lamellar hole is a relatively stable condition in highly myopic eyes [15]. Also, the subsequent development of retinal schisis might further reduce the traction force in a similar way. As indicated in Figure 1e and f, at the final follow-up, the retina was reattached with the presence of posterior hyaloid traction; therefore, the traction force was not released but was reduced by the development of a lamellar hole and foveal schisis.

It remains unclear whether surgical intervention could improve the visual outcomes. As evidenced by the current case, nevertheless, spontaneous closure of a macular hole and complete retinal reattachment can occur in a myopic eye. Future study with more cases might further improve our knowledge of this entity.

\section{Consent}

Written informed consent was obtained from the patient for publication of this case report and any accompanying images. A copy of the written consent is available for review by the Editor of this journal.

\section{Abbreviations}

OCT: Optical coherence tomography; RPE: Retinal pigment epithelium.

\section{Competing interests}

Dr. Chunhui Jiang, and Dr. Gezhi Xu received \$200 and \$400 speaker honorariums, respectively, from the Zeiss Company in the past 2 years.

\section{Authors' contributions}

JY: Acquisition, analysis and interpretation of the data; literature search and writing the article. CJ: Conception and design of the study; acquisition, analysis and interpretation of the data; writing the article and final approval of the article. GX: Conception and design of the study, critical revision and final approval of the article. All authors read and approved the final manuscript.

\section{Authors' information}

Dr. Chunhui Jiang conducts one project of Shanghai Committee of Science and Technology, and Dr. Gezhi Xu conducts 2 projects supported by National Key Basic Research Program of China and Shanghai Key Laboratory of Visual Impairment and Restoration, Fudan University, Shanghai, China, respectively.

\section{Acknowledgements}

The collection, analysis and interpretation of data as well as the writing and preparation of the manuscript was funded by Shanghai Committee of Science and Technology (Grant No. 13430710500), National Key Basic Research Program of China (Grant No.2013CB967503) and Shanghai Key Laboratory of Visual Impairment and Restoration, Fudan University, Shanghai, China (Grant No.12DZ2260500)

\section{Author details}

'Department of Ophthalmology, Eye \& ENT Hospital of Fudan University, 83 Fenyang Road, Shanghai 200031, People's Republic of China. ${ }^{2}$ Shanghai Key Laboratory of Visual Impairment and Restoration, Fudan University, Shanghai, China.

Received: 17 July 2014 Accepted: 16 September 2014 Published: 18 September 2014

\section{References}

1. Morita H, Ideta H, Ito K, Yonemoto J, Sasaki K, Tanaka S: Causative factors of retinal detachment in macular holes. Retina 1991, 11:281-284.

2. Li X, Wang W, Tang S, Zhao J: Gas injection versus vitrectomy with gas for treating retinal detachment owing to macular hole in high myopes. Ophthalmology 2009, 116:1182-1187. e1.

3. Nakanishi H, Kuriyama S, Saito I, Okada M, Kita M, Kurimoto Y, Kimura H, Takagi H, Yoshimura N: Prognostic factor analysis in pars plana vitrectomy for retinal detachment attributable to macular hole in high myopia: a multicenter study. Am J Ophthalmol 2008, 146:198-204.

4. Ikuno Y, Sayanagi K, Oshima T, Gomi F, Kusaka S, Kamei M, Ohji M, Fujikado T, Tano Y: Optical coherence tomographic findings of macular holes and retinal detachment after vitrectomy in highly myopic eyes. $\mathrm{Am} J$ Ophthalmol 2003, 136:477-481.

5. Ripandelli G, Coppé AM, Fedeli R, Parisi V, D'Amico DJ, Stirpe M: Evaluation of primary surgical procedures for retinal detachment with macular hole in highly myopic eyes: a randomized comparison of vitrectomy versus posterior episcleral bucking surgery. Ophthalmology 2001, 108:2258-2264.

6. Inoue M, Arakawa A, Yamane S, Watanabe Y, Kadonosono K: Long-term outcome of macular microstructure assessed by optical coherence tomography in eyes with spontaneous resolution of macular hole. Am J Ophthalmol 2012, 153:687-691.

7. Punjabi OS, Flynn HW Jr, Legarreta JE, Gregori G, Knighton RW, Puliafito CA: Documentation by spectral domain OCT of spontaneous closure of idiopathic macular holes. Ophthalmic Surg Lasers Imaging 2007, 38:330-332.

8. Imai M, Ohshiro T, Gotoh T, Imasawa M, lijima H: Spontaneous closure of stage 2 macular hole observed with optical coherence tomography. Am J Ophthalmol 2003, 136:187-188.

9. Li Y, Jonas JB, Lu L: Spontaneous closure of highly myopic macular hole associated with retinal detachment. Acta Ophthalmol 2014, 92:e408-e410.

10. Ip MS, Baker BJ, Duker JS, Reichel E, Baumal CR, Gangnon R, Puliafito CA: Anatomical outcomes of surgery for idiopathic macular hole as determined by optical coherence tomography. Arch Ophthalmol 2002, 120:29-35.

11. Alkabes M, Padilla L, Salinas C, Nucci P, Vitale L, Pichi F, Burès-Jelstrup A Mateo C: Assessment of OCT measurements as prognostic factors in myopic macular hole surgery without foveoschisis. Graefes Arch Clin Exp Ophthalmol 2013, 251:2521-2527.

12. Benhamou N, Massin P, Haouchine B, Erginay A, Gaudric A: Macular retinoschisis in highly myopic eyes. Am J Ophthalmol 2002, 133:794-800.

13. Baba T, Ohno-Matsui K, Futagami S, Yoshida T, Yasuzumi K, Kojima A, Tokoro T, Mochizuki M: Prevalence and characteristics of foveal retinal detachment without macular hole in high myopia. Am J Ophthalmol 2003, 135:338-342. 
14. Akiba J, Konno S, Yoshida A: Retinal detachment associated with a macular hole in severely myopic eyes. Am J Ophthalmol 1999, 128:654-655.

15. Tanaka Y, Shimada N, Moriyama M, Hayashi K, Yoshida T, Tokoro T, Ohno-Matsui K: Natural history of lamellar macular holes in highly myopic eyes. Am J Ophthalmol 2011, 152:96-99. e1.

doi:10.1186/1471-2415-14-111

Cite this article as: Yu et al.: Spontaneous closure of a myopic macular hole with retinal reattachment in an eye with high myopia and staphyloma: a case report. BMC Ophthalmology 2014 14:111.

\section{Submit your next manuscript to BioMed Central} and take full advantage of:

- Convenient online submission

- Thorough peer review

- No space constraints or color figure charges

- Immediate publication on acceptance

- Inclusion in PubMed, CAS, Scopus and Google Scholar

- Research which is freely available for redistribution 